\title{
An Update on Three-Dimensional CT Angiography in Aneurysms: A Useful Modality for a Neurosurgeon
}

\author{
Anevrizmalarda Üç Boyutlu BT Anjiyografi ile Ilgili Bir Güncelleme: \\ Bir Beyin Cerrahı İcin Yararlı Bir Yöntem
}

Ashish KUMAR ${ }^{1}$, Yoko KATO², Hayakawa MOTOHARU², Chen SIFANG ${ }^{3}$, Oda JUNPEI², Watabe TAKEYA², Imizu SHUEI ${ }^{2}$, Oguri DAIKICHI ${ }^{2}$, Hirose YUICHI ${ }^{2}$

${ }_{1}^{1}$ Bombay Hospital Institute of Medical Sciences, Department of Neurosurgery, Mumbai, India

${ }^{2}$ Fujita Health University Hospital, Department of Neurosurgery, Toyoake, Japan

${ }^{3}$ The First Affiliated Hospital of Xiamen University, Department of Neurosurgery, Xiamen, China

Corresponding Author: Ashish KUMAR / E-mail: ashish_med@rediff.com

\begin{abstract}
The role of three-dimensional computed tomography angiography (3D-CTA) in management of aneurysms has been fairly acknowledged in the past. There have been numerous articles in the literature regarding its potential threat to the conventional "gold standard", i.e. digital subtraction angiography (DSA). We study the technology used at a tertiary care hospital in Japan which performs a large number of aneurysm surgeries a year and review the recent literature to gain an insight into the current role of 3D-CTA in detection of aneurysms and if it can be a front line modality of investigation from a neurosurgeon's point of view. At many centres including those in India, DSA is still treated as the first choice of investigation. Although 3D CTA has some limitations, it can provide an unmatched multi-directional view of the aneurysmal morphology and its surroundings including relations with the skull base and blood vessels. This may provide an invaluable help to a neurosurgeon who is usually concerned about many other associated factors involved in approaching an aneurysm.
\end{abstract}

KEYWORDS: Aneurysm, Subarachnoid hemorrhage, Computed tomography angiography

\section{Öz}

Üç boyutlu bilgisayarlı tomografi anjiyografinin (3D-BTA) anevrizmaların tedavisindeki rolü uzun zamandır kabul edilmektedir. Geleneksel "altın standart", yani dijital subtraksiyon anjiyografi (DSA) için potansiyel bir tehdit olması ile ilgili literatürde çok sayıda makale vardır. Biz yıllık anevrizma ameliyatı sayısı oldukça yüksek olan, Japonya'da üçüncü basamak bir hastanede kullanılan teknolojiyi incelemek ve anevrizmaların saptanmasında 3D-BTA'nın mevcut rolüne bir bakış açısı kazanabilmek ve bir beyin cerrahı bakış açısından bunun önde gelen bir inceleme yöntemi olup olamayacağını tespit etmek için son literatürü gözden geçirmek istiyoruz. Hindistan'dakiler dahil olmak üzere birçok merkezde, DSA halen incelemede ilk seçenektir. 3D CTA bazı sınırlamalar olmasına rağmen anevrizmanın morfolojisi ve kafa tabanı ve kan damarları ile ilişkileri de dahil olmak üzere çevresi hakkında çok yönlü eşsiz bir görünüm sağlayabilir. Bu genellikle, anevrizmaya yaklaşımla ilgili pek çok faktörü birarada düşünen bir beyin cerrahı için paha biçilmez bir yardım sağlayabilir.

ANAHTAR SÖZCÜKLER: Anevrizma, Subaraknoid kanama, Bilgisayarlı tomografi anjiyografi

\section{INTRODUCTION}

Subarachnoid Hemorrhage (SAH) still accounts for high mortality rates even in the presence of the modern technology and facilities at our disposal. The incidence of SAH has been around 10-15 per 100,000 person-years and has shown a downward trend off late due to early detection and management of un-ruptured aneurysms. There are three important diagnostic modalities available at present for the pre-operative assessment of these aneurysms. These are DSA (Digital Subtraction Angiography), CTA (Computed Tomography Angiography) and the MRA (Magnetic Resonance Angiography). While the MRA has clearly an advantage of not exposing the patient to radiation, it has got its own limitations in terms of the time required for the study and associated artifacts. Three-dimensional computed tomography angiography (3D-CTA) with 64 slice multidetector row computed tomography (MDCT) has been really beneficial in the pre-operative assessment of both ruptured and un-ruptured aneurysms. Moreover, a neurosurgeon usually has many other associated dilemmas during an aneurysm surgery and CTA can be helpful in clearing few of them. These may include a spectrum of issues like the approach, surrounding vascular anatomy (including the perforators in the vicinity) and the nearby bony structures. Although the debate will never cease to exist, CTA has been found useful in converting its advantages into patients benefit. We review the most recent literature in this context and try to figure out the answer. 


\section{Available Diagnostic Options: MRA, DSA or 3D-CTA?}

The role of MRA has been limited in SAH. However, it may be found useful especially for screening patients with a positive family history of subarachnoid hemorrhage (SAH). Fluid attenuated inversion recovery (FLAIR) images may detect blood pigments better than the $\mathrm{CT}$ in sub-acute and delayed cases of SAH (10). In acute SAH however, it may not be feasible as it is often time- consuming and requires utmost patient cooperation. Also, it has an inferior resolution than the other modalities and cannot be performed in patients with metallic implants, pacemakers and those with claustrophobia. The "gold standard" DSA however can be performed under local anaesthesia, has got a good resolution and can demonstrate perforators and surrounding vessels near the aneurysm. It can also pick up smaller vessels $(<2 \mathrm{~mm})$ more accurately. Also, for examining the 'dynamic' cross-circulation, diagnostic and therapeutic treatment of vasospasm (chemical angioplasty) DSA may be found useful. The chief disadvantage is its invasiveness. Literature quotes significant stroke related morbidity due to embolic phenomenon especially in older patients with atherosclerotic vessels. The risk is between 0.1 to $2.6 \%$ in healthy patients and increases 2.5 -fold in patients above 60 years with occlusive cerebrovascular disease (5). Also, it may become difficult in uncooperative patients. The other pitfall of the DSA is in demonstrating partial or complete thrombosis of an aneurysm. In comparison, 3D-CTA is the least invasive. Here, patients undergo a helical CT scan and if SAH is detected, it is immediately followed by an angiographic study which further undergoes post-procedural reformatting in the form of maximal intensity projections (MIP), volume rendering techniques (VRT) and virtual reality images. The morphology of the aneurysm including the size, shape, direction, wall regularity, calcification, thrombosis, penetrating branches and nearby perforators is studied extensively. Also, the relationship of the aneurysm to the bone can be best studied with the help of 3D-CTA. The surgeon finds it helpful in pre-operative planning by rotating the image in a three dimensional way and by removing the bone slice by slice that sometimes obscures a part of aneurysm. This is done by the surgeon himself and is usually done on CT console itself. The pictures are taken from the superior, inferior, right and left lateral, anterior and posterior aspects and also simulated for the pre-decided surgical approach. This allows visualizing the orientation of aneurysm and nearby vessels mentally before the surgery from the desired approach and can help in certain modifications to it, if needed.

The well-known advantages of 3D-CTA are:

1. Non-invasiveness

2. Easy availability and economical

2. Rapid acquisition within 2 minutes; doesn't require anaesthesia.

3. Good resolution

4. Calcifications and thrombosed aneurysms can be identified in a better way.
The chief disadvantages being:

1. Dye allergy

2. Nephrotoxicity

3. Non-detection of small vessels $(<1.2 \mathrm{~mm})$

5. Post procedural reformatting from the raw data is required.

\section{DISCUSSION}

Siddiqui et al. reviewed the diagnostic efficacy of 3D-CTA over DSA and found CTA extremely useful in all but few occasions (9). Nagai and Watanabe used only 3D-CTA to evaluate the suitability of multi-detector CT (MDCT) angiography for preoperative evaluation (7). The surgeon himself formatted the CTA and rotated the 3D image for his orientation. The sphenoid ridge was removed partially to simulate the surgical view. For any patient where the CTA was negative, conventional DSA was performed. Thereafter, all anterior circulation aneurysms were taken directly for surgery while posterior circulation ones were referred for coil embolization. One patient with no aneurysm seen on CTA underwent DSA twice to identify the aneurysm. Two parameters were assessed in the study. One was the sensitivity of CTA in detecting aneurysms in patients of $\mathrm{SAH}$ and the other was the time between admission and entering the operating room. The sensitivity of 3D-CTA was $100 \%$ and shapes of all the aneurysms depicted by it were validated intra-operatively. The false negative rate was $0 \%$. The mean operation waiting time was 2.8 hours with the shortest being 1.5 hours. The mean time in the DSA group was 4.1 hours. Almost $60 \%$ of aneurysmal rupture occurs within 6 hours after the initial ictus and DSA within first 6 hours has been associated with a risk of re-bleeding (2-5\%). Thus, CTA in this interval can be extremely useful.

In another interesting study, a retrospective analysis of the mortality rates of patients with SAH done for a 10 year period, an average fatality rate of $24.2 \%$ in $1999-2002$ declined to $15.9 \%$ in $2005-2008(p=0.016)^{8}$. Amongst the various factors, like improved management of patients and enhanced surgical techniques, one of the factors stated was the transition from DSA to 3D-CTA. In the earlier group, 55.3\% patients underwent diagnostic DSA and $23 \%$ patients were diagnosed from CTA. While in the latter group, 70\% patients underwent CTA and only $13.7 \%$ patients underwent DSA $(p<0.0001)$. This is one of the few studies contemplating the possible indirect effect of investigative modalities on the morbidity and mortality rates of SAH due to early surgery. The technology, surgical expertise and the efficient post operative management of SAH patients has also evolved over the years leading to better results in complex aneurysms and in poor grade patients. Mo et al. (6) used a virtual reality (VR) system (Dextroscope; Volume Interactions Pte. Ltd.,Singapore) with 3D-CTA to diagnose and study the aneurysmal morphology and its relationships to other vessels. The VR system generated clear and vivid 3-D virtual images that clearly displayed the location and size of the aneurysms and their precise anatomical spatial relations to the parent arteries and skull. A total of 8 patients with 
13 aneurysms were studied with pre-operative 3D-CTA by Khan et al. (4) All the pre-operative findings were confirmed during the surgery. Diagnostic accuracy was referred to the accuracy of identifying cerebral aneurysms, their surrounding vascular anatomy, the presence of vasospasm and whether the aneurysm had a clearly definable sac and neck. 3D-CTA was found to be $100 \%$ diagnostically accurate in revealing surrounding anatomy including blebs, lobes and nearby vessels. Also, it was found to be $92.3 \%$ sensitive in detecting and planning the feasibility of clipping. However, in contrast Kallmes et al. (3) concluded that the results of CTA were sub-optimal in detecting aneurysms. They quoted a false negative rate as high as $10 \%$ leading to an additional 2.5 deaths per 100 patients because of re-hemorrhage from undetected aneurysms. The spatial resolution of CTA is in the range of $0.35-0.5 \mathrm{~mm}$ as compared to $0.2-0.3 \mathrm{~mm}$ of $3 \mathrm{D}$ rotational angiography and $0.1 \mathrm{~mm}$ of conventional DSA. Also, the anterior choroidal and heubner's arteries may not be visualized on CTA and aneurysms of these vessels can thus be missed leading to non-diagnosis. Interestingly, Agid et al (1) evaluated the role of 3D-CTA in triaging patients of $\mathrm{SAH}$. CTA detected aneurysms in 46 of the 47 patients (sensitivity of $98 \%$, specificity of $100 \%$, positive predictive value of $100 \%$ and negative predictive value of $82.3 \%$ ). In $95.7 \%$ patients, treatment was done using CTA alone while in $4.4 \%$ patients; it was inconclusive requiring a DSA. Triaging the patients for either surgery or endovascular treatment depends on the morphology of aneurysms which could be better assessed after the VR formatting. Daughter blebs can be better analyzed apart from the morphometry and these may preclude coil placement in select cases. 3D-CTA and DSA have been compared for detection of post clipping neck remnants, residual aneurysms and parent vessel occlusion (2). On DSA, 35 were found to be completely obliterated, 10 had neck remnants and 8 had residual aneurysms. The ability of CTA to detect residual aneurysms versus complete obliterations was excellent (mean sensitivity, 88\%; specificity, 100\%; positive predictive value [PPV], 100\%; negative predictive value [NPV], 98\%). However, the study showed that it remained poor in detecting neck remnants. This could be due to clip artifacts secondary to the cobalt alloy clips that were used in majority of cases in this study. These days, with the use of titanium clips, such artifacts have been reduced substantially and thus better results would be expected.

\section{Our Experience}

At our tertiary care hospital and referral centre, 3D-CTA is done for pre-operative planning of ruptured and un-ruptured aneurysms and nearly all the findings of the CTA remain concordant with findings observed during the surgery. Thus, the 3D-CTA has become the front line modality of investigation as far as pre-operative assessment of aneurysms is concerned. Multiple views are taken along with the skull base after formatting / volume rendering and complex aneurysms involving the anterior communicating artery $(A C A)$, posterior communicating artery (PCA) and internal carotid artery (ICA) can be seen with excellent resolution and their relationship to any vessel which is adhered to the dome can be studied (Figure 1). Also, middle cerebral artery (MCA) aneurysms and their relation with early branches can be studied in detail (Figure 2). Aneurysms involving the basilar apex and its distance from the posterior clinoid process (15.8 $\mathrm{mm}$ in this patient) can be better assessed (Figure 3). This can be particularly useful for high basilar top aneurysms and could lead to change in operative strategy like incorporating an FTOZ (Fronto-Temporo-Orbital-Zygotomy) approach for

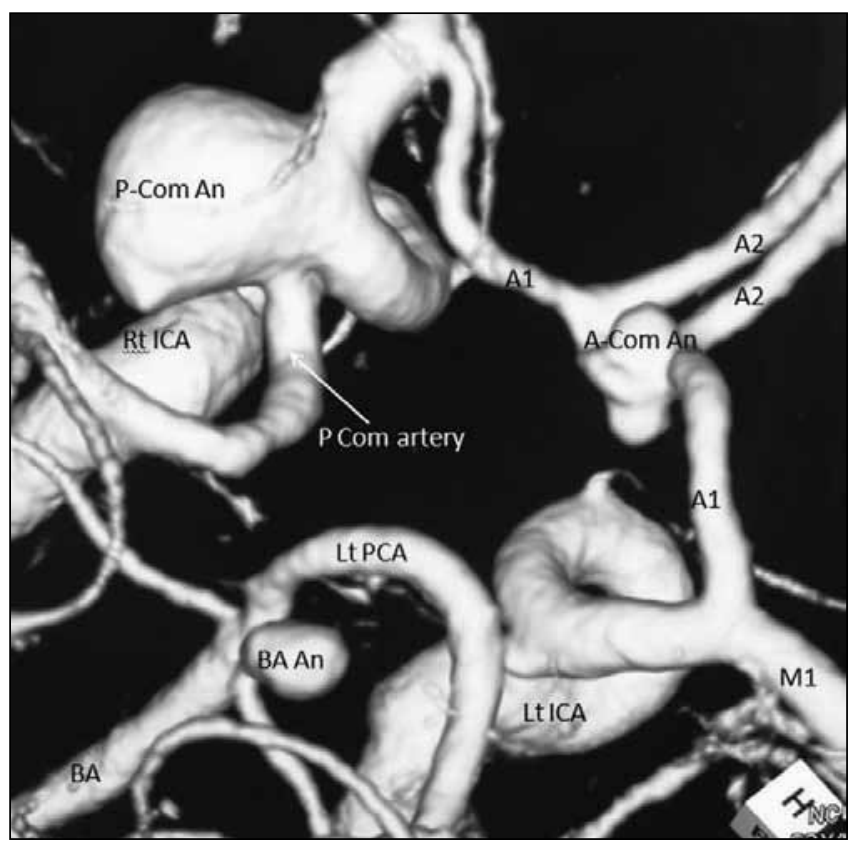

Figure 1: Anterior (A-com An) and posterior communicating aneurysm ( $\mathrm{P}$-Com An)along with a basilar aneurysm (BA An) in a patient with lateral view showing $\mathrm{p}$-com artery arising from the aneurysmal dome.A1,A2,M1,M2,ICA and BA are seen as well.

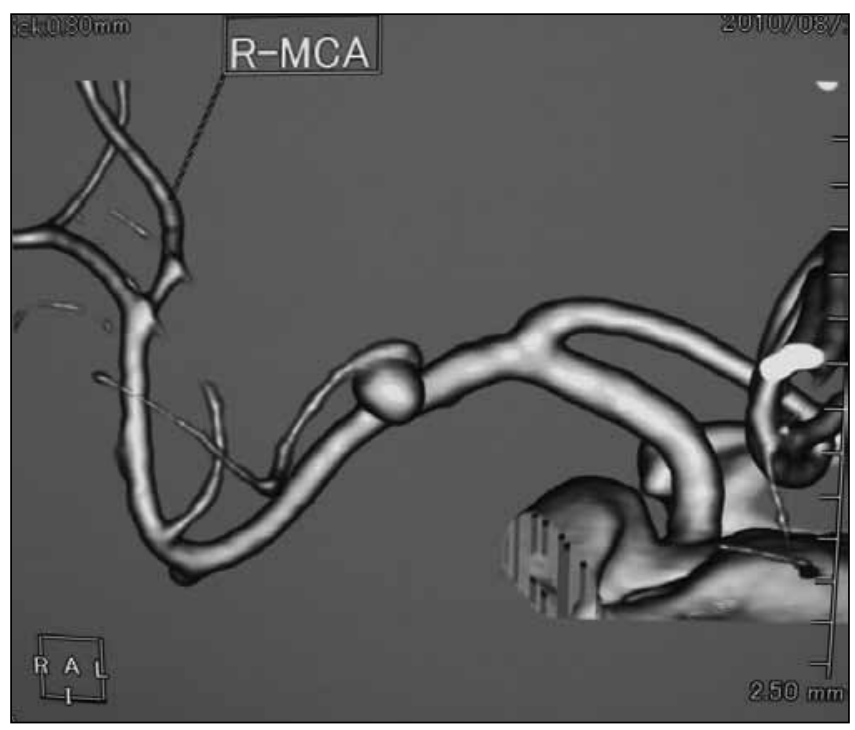

Figure 2: Middle cerebral artery ( $M-1$ segment) aneurysm and a proximal branch adhered to the dome seen from anterior projection. 
such cases. Daughter blebs requiring special attention and bilobed aneurysms (Figure 4,5) can also be evaluated (as they may be the weak points for a potential aneurysmal rupture). Aneurysms from anterior choroidal artery mayalso be detected by reducing the threshold (Figure 6). Operative simulation is done before the surgery. This is done after subtracting the proposed craniotomy bone from the image and rotating it as for example, a pterional craniotomy (Figure 7). This helps

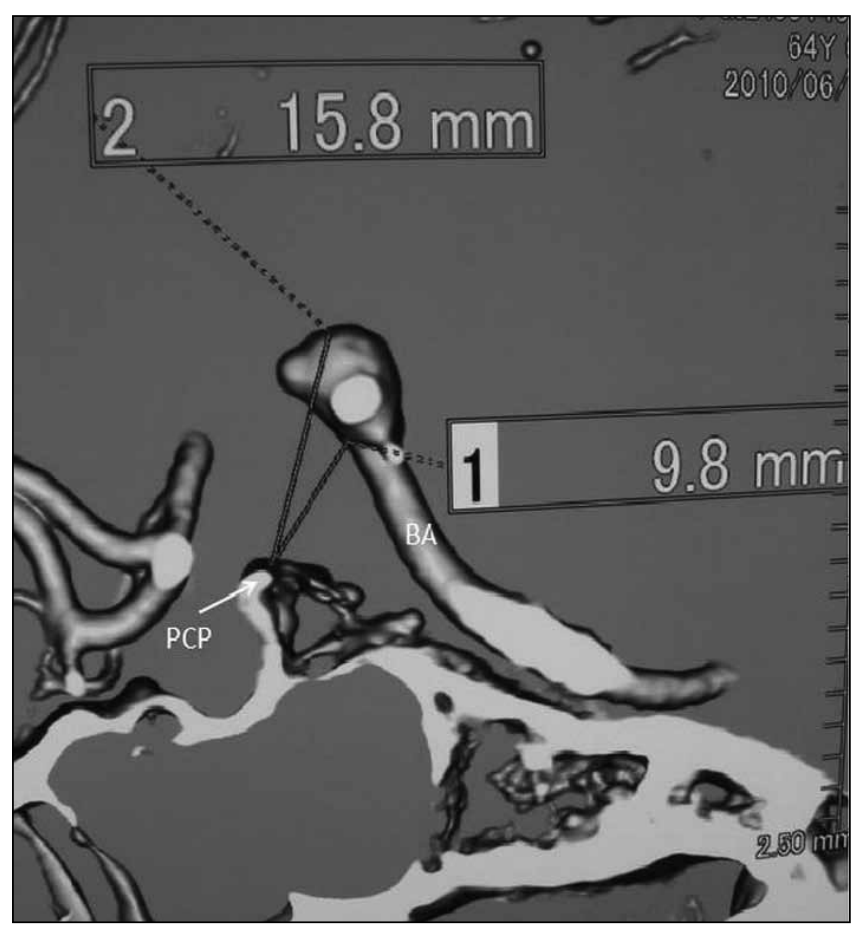

Figure 3: Lateral view showing the distance of basilar top aneurysm above the posterior clinoid process (PCP).

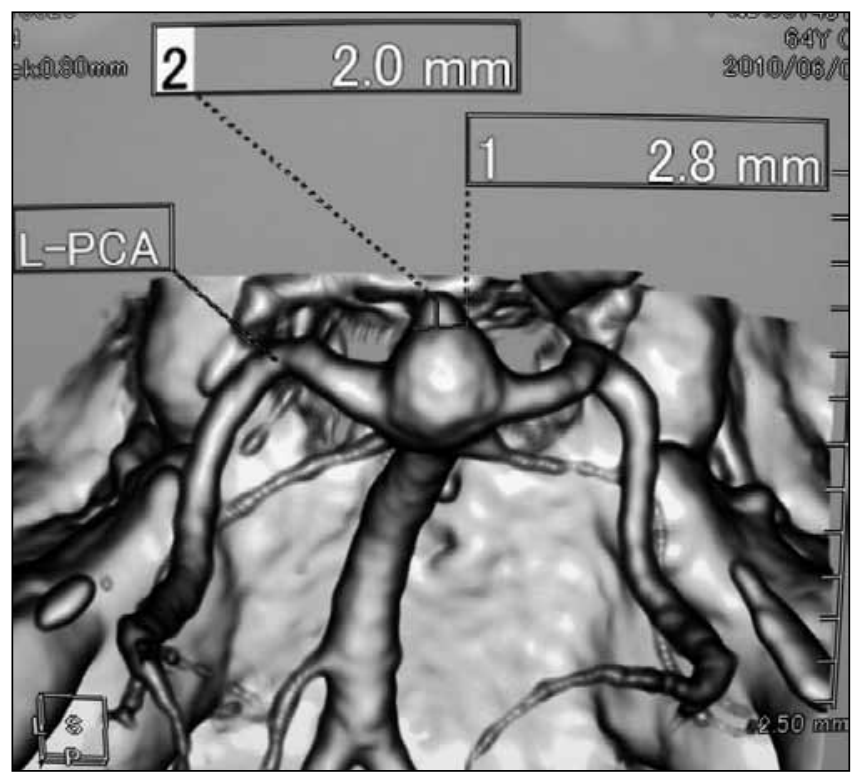

Figure 4: Same basilar top aneurysm with a daughter bleb of $2 \mathrm{~mm}$ projecting anteriorly. the surgeon to orient himself regarding the position of the neck and dome of the aneurysm. In cases of large ophthalmic aneurysms, even the extent of anterior clinoid process (ACP) drilling can be pre-assessed (Figure 8). Their relation with the tiny ophthalmic artery can also be visualized in many cases (Figure 9). In cases of large MCA aneurysms directed anteriorly (Figure 10), the distance from the sphenoid ridge may be better assessed and hence special care may be deemed necessary during the sphenoid wing drilling. All these findings usually co-relate well intra-operatively

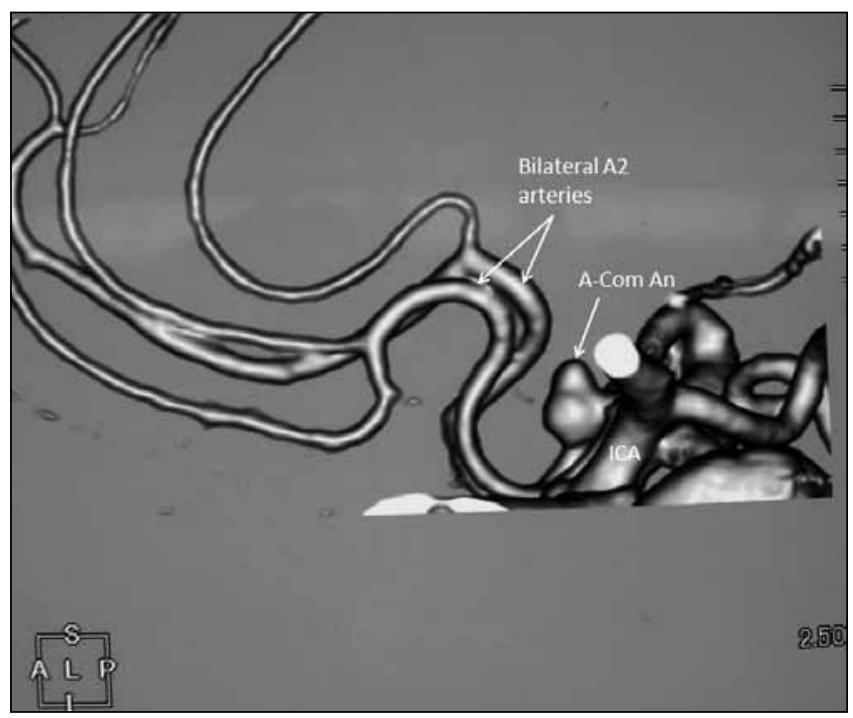

Figure 5: Bi-lobed A-com aneurysm with both distal A2 arteries.

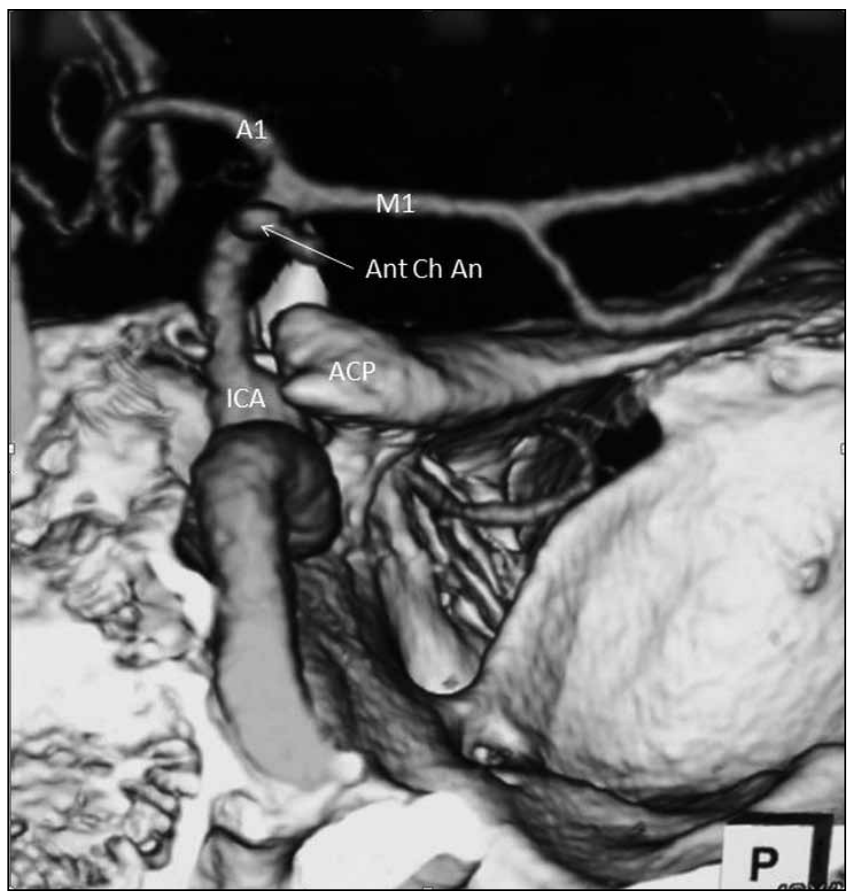

Figure 6: Posterior view showing anterior choroidal aneurysm. Anterior Clinoid Process (ACP) and ICA with $A 1$ and $M 1$ segments visualized. 
(Figure 11). Branches arising from the parent artery and neck of an aneurysm both are well delineated so that the neck is reformed during clip application (Figure 12). Even fetal posterior circulation could be seen very well on 3D-CTA (Figure 13). This may prevent inadvertent damage to the PCA during dealing with posterior communicating segment aneurysms. A large MCA aneurysm with small perforators stuck on its wall could be correlated well during the surgery (Figure 14). Similarly useful venous anatomy could also be detected at times with good intraoperative correlation (Figure 15). When compared to the Digital Subtraction Angiography (DSA), large and giant

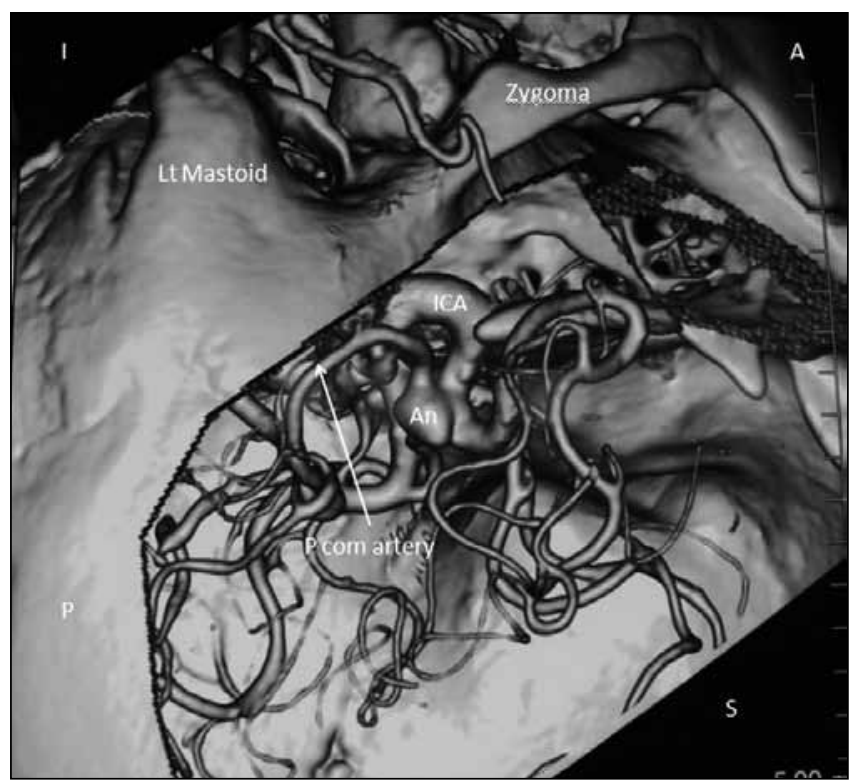

Figure 7: Simulation for a Left pterional craniotomy to approach post communicating ICA aneurysm where $\mathrm{p}$-com artery is arising from the dome of aneurysm. Anterior $(A)$, posterior $(P)$, superior (S) and inferior (I) directions are shown. The figure correlates well intra-operatively.

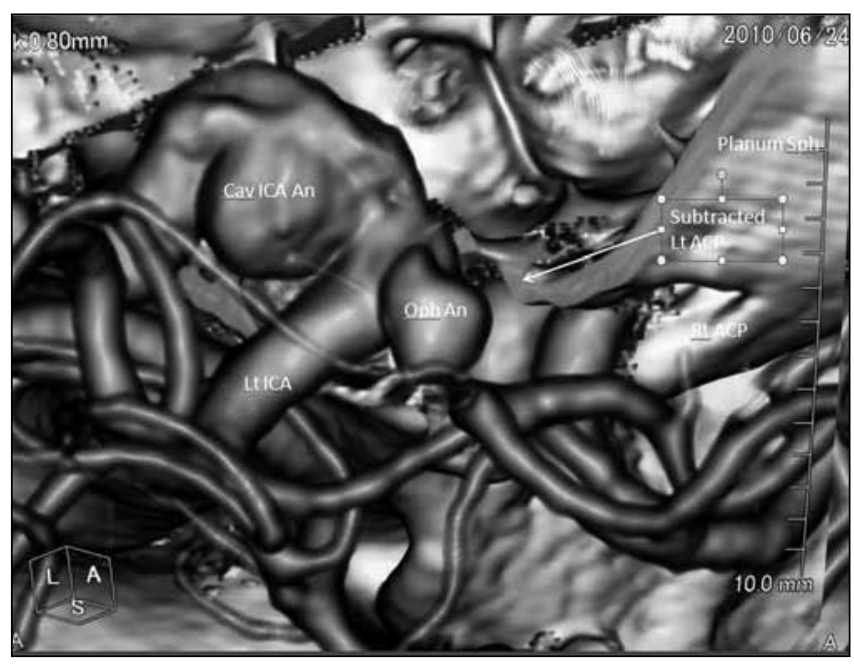

Figure 8: Antero-lateral view showing ophthalmic segment ICA aneurysm with ipsilateral ACP subtraction; another cavernous segment ICA aneurysm seen. internal carotid aneurysms can be visualized in relation to the ACP and its vertical extent into the cavernous sinus may be determined (Figure 16). Fetal anomalies like Persistent Trigeminal Artery (PTA) can be picked up and these may be crucial in some cases (Figure 17). Based on all these findings on 3D-CTA, a surgeon is usually able to better orient himself before the surgery.

\section{Technical Details:}

The 3D CTA is performed using 320 row area detector CT Aquilon one (Toshiba Medical Co., Ltd) with following parameters:

$120 \mathrm{kV} / 270 \mathrm{~mA}$

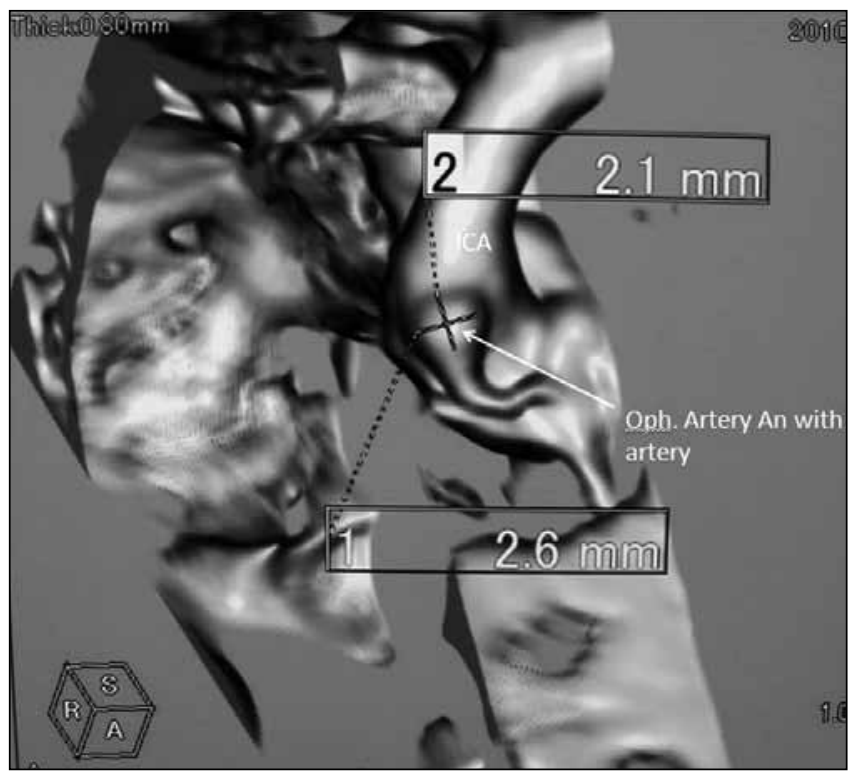

Figure 9: Ophthalmic artery aneurysm with artery arising from its wall.

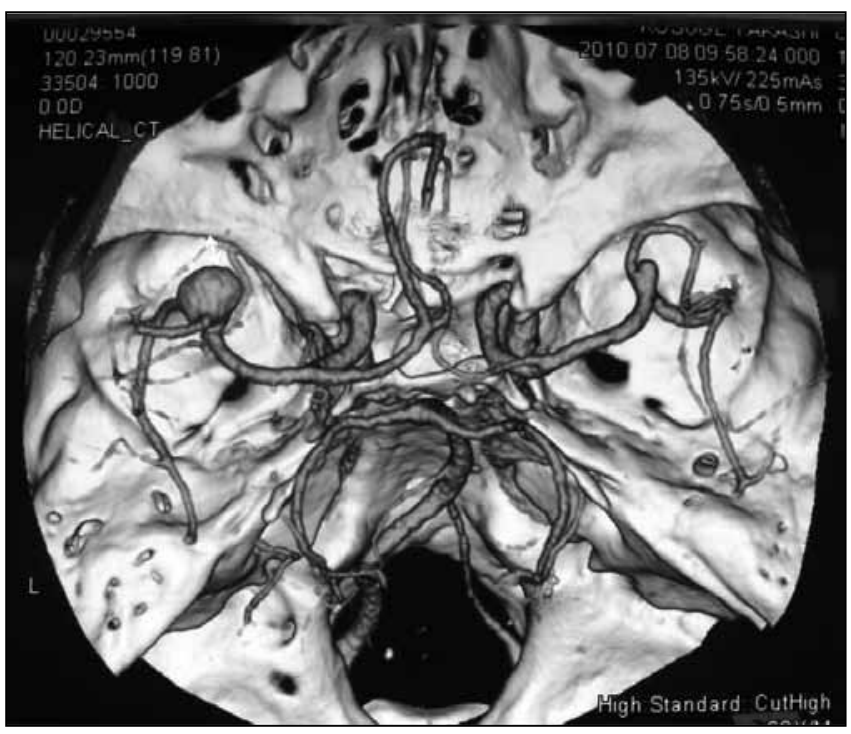

Figure 10: Right MCA aneurysm at the bifurcation shortly away from sphenoid ridge (arrow). 
Slice thickness: $0.5 \mathrm{~mm}$

Scan speed: $1.0 \mathrm{sec} / \mathrm{cycle}$

Scan range: $8.0 \mathrm{~mm}$ from foramen magnum

Scan triggering: Sure Start function

Reconstruction pitch: $0.5 \mathrm{~mm}$

Target reconstruction: FOV=24 cm (Side: M2-M3; Front: A2-A3; Post: VA-pica)

3D workstation: Toshiba extension (San Spark 20)

Algorithm: Volume rendering

3D image: standard 11 projections + additional projection

\section{SUMMARY}

Although there is no doubt regarding the age-old utility

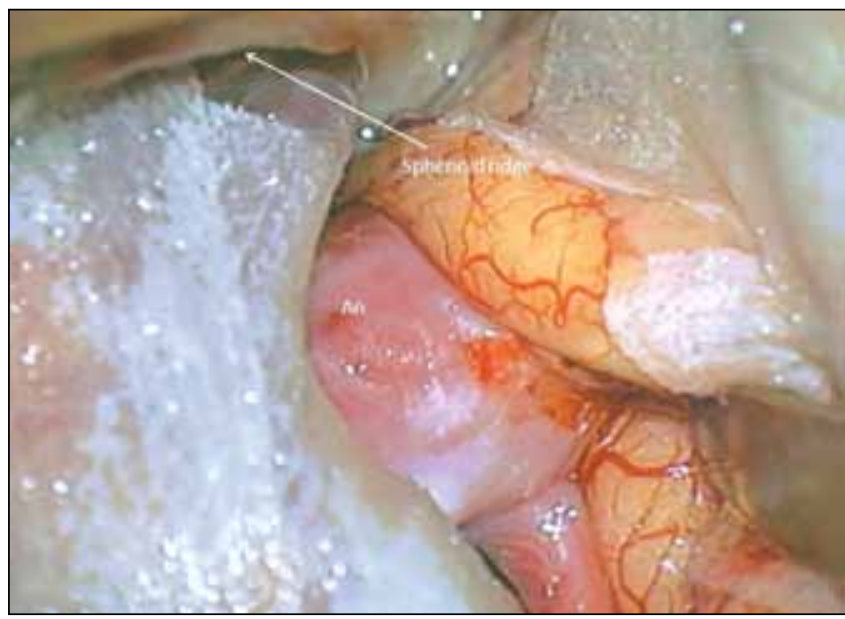

Figure 11: Intra-operative correlation of the same MCA aneurysm showing its proximity to sphenoid ridge.

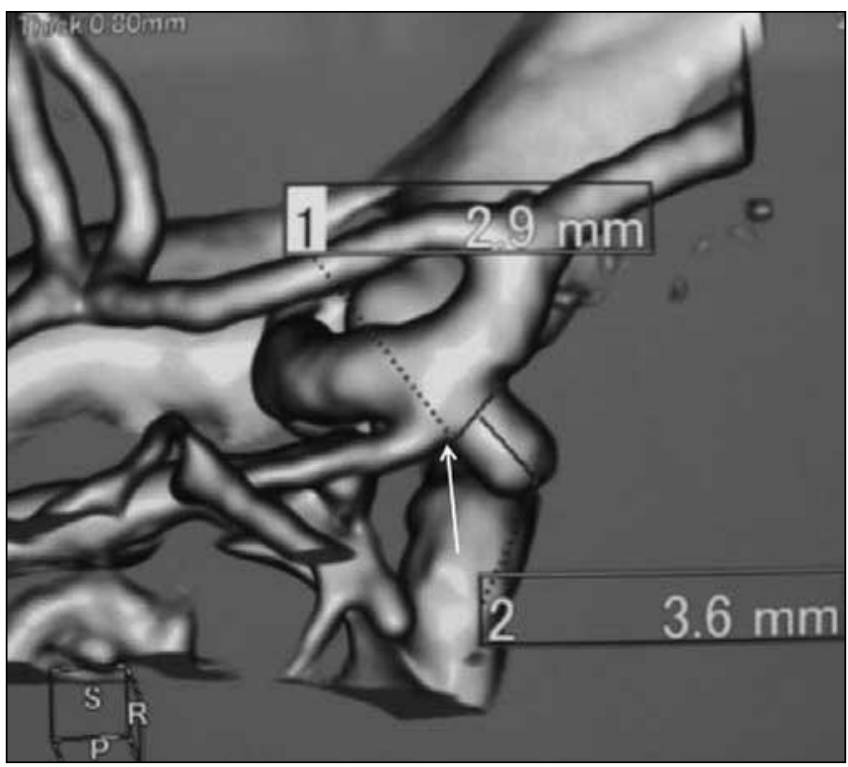

Figure 12: Aneurysm incorporating the wall of the parent artery and neck of the aneurysm (arrow). The neck needs to be reformed with multiple clips. of DSA, 3D-CTA in a good setup can become a first line investigating modality that could help a surgeon in more than one way. It could vary from triaging patients for coiling/ clipping to forming a mental framework of the surrounding bony and vascular anatomy to get 'the surgeon's view'. However, at many centres, the resolution may remain a major limitation in detecting small aneurysms and perforators and

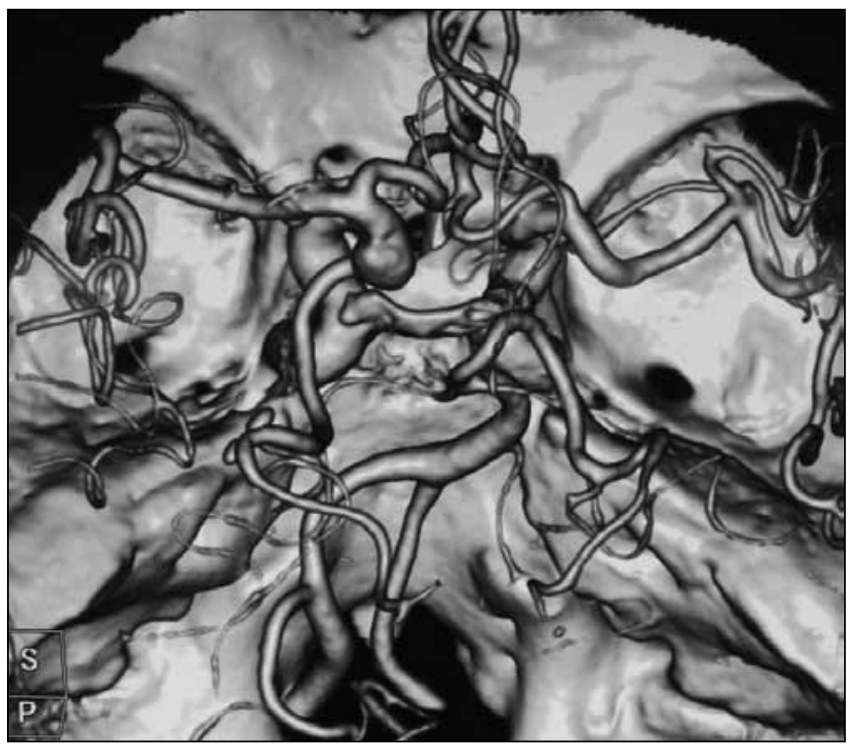

Figure 13: Fetal Circulation seen with P-com continuing as Right PCA.

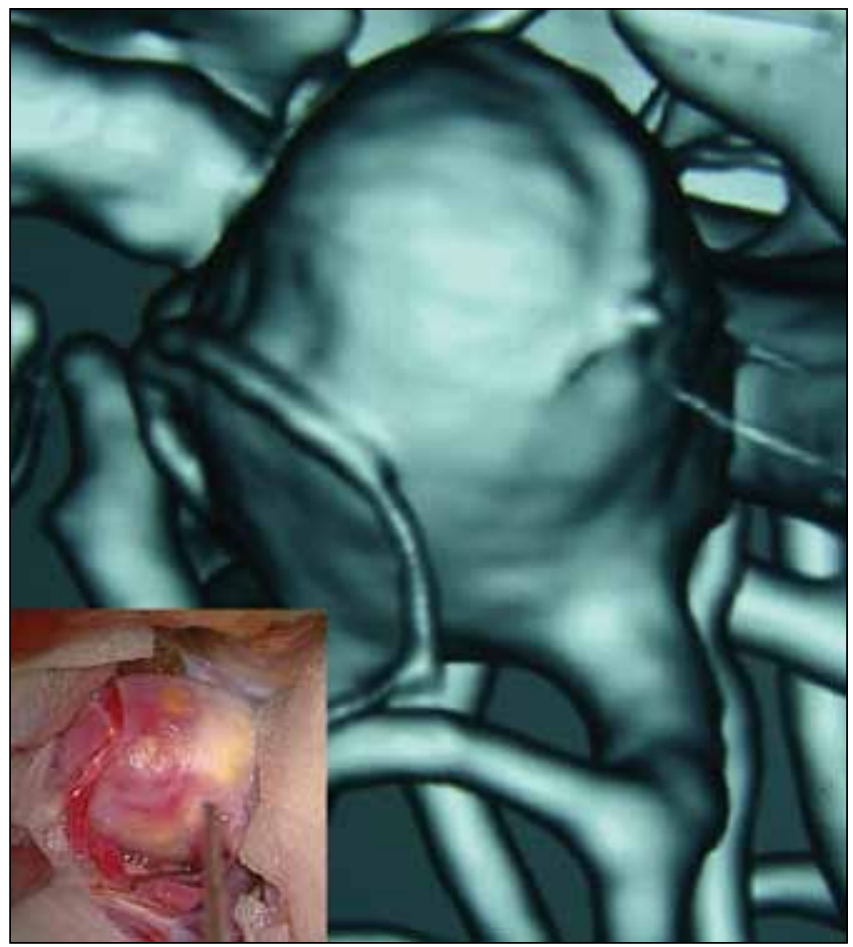

Figure 14: A large MCA aneurysm with two perforators stuck to its wall as seen on 3D-CTA with good intra-operative correlation (inset). 


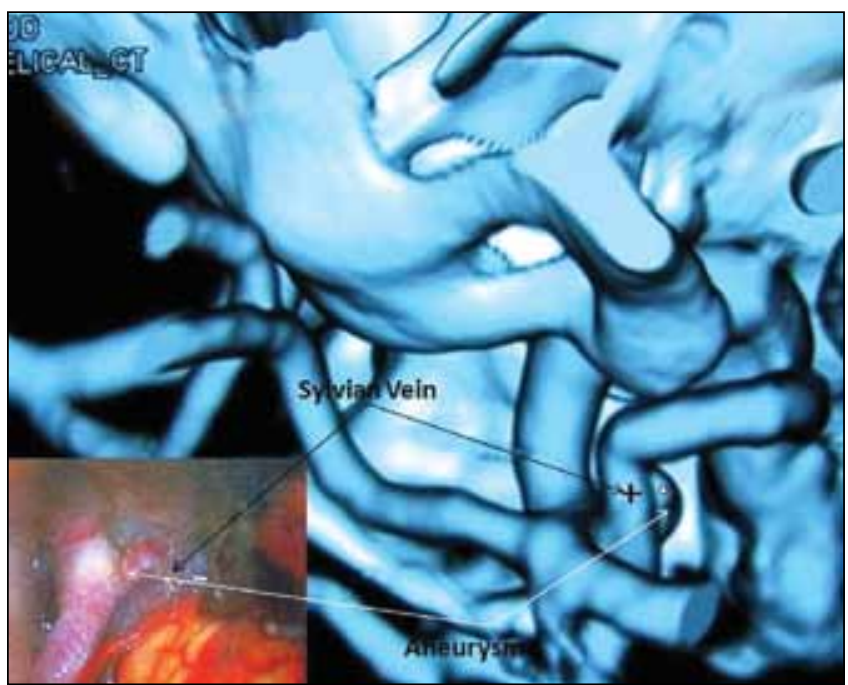

Figure 15: Sylvian vein (cross) obscuring the dome of a p-com aneurysm (white square) correlated well during surgery (inset). hence the fusion of the latest technology ( 64 slice MDCT) and sharp intellectual assessment remains paramount.

The fact that the rapidity with which a CTA can provide a result within 6 hours of the ictus (where a DSA may be avoided) and thus shortening the time to surgery cannot be ignored. Patients can avoid two invasive procedures if a coiling procedure is planned. However, smaller vessels would be better appreciated by the DSA and it also remains a procedure of choice for postoperative assessment of clipped aneurysms (especially for assessment of neck remnants). Although the recent literature has given initial insights in favour of CTA as a less invasive modality indirectly affecting the mortality/ morbidity rates associated with aneurysmal $\mathrm{SAH}$, we may have to wait for further studies to assess its direct impact on mortality/morbidity rates. A neurosurgeon may benefit by the whole spectrum of information rendered by 3D-CTA apart from the aneurysmal morphology alone, which will help him/ her in approaching the surgery in a better and safe manner.

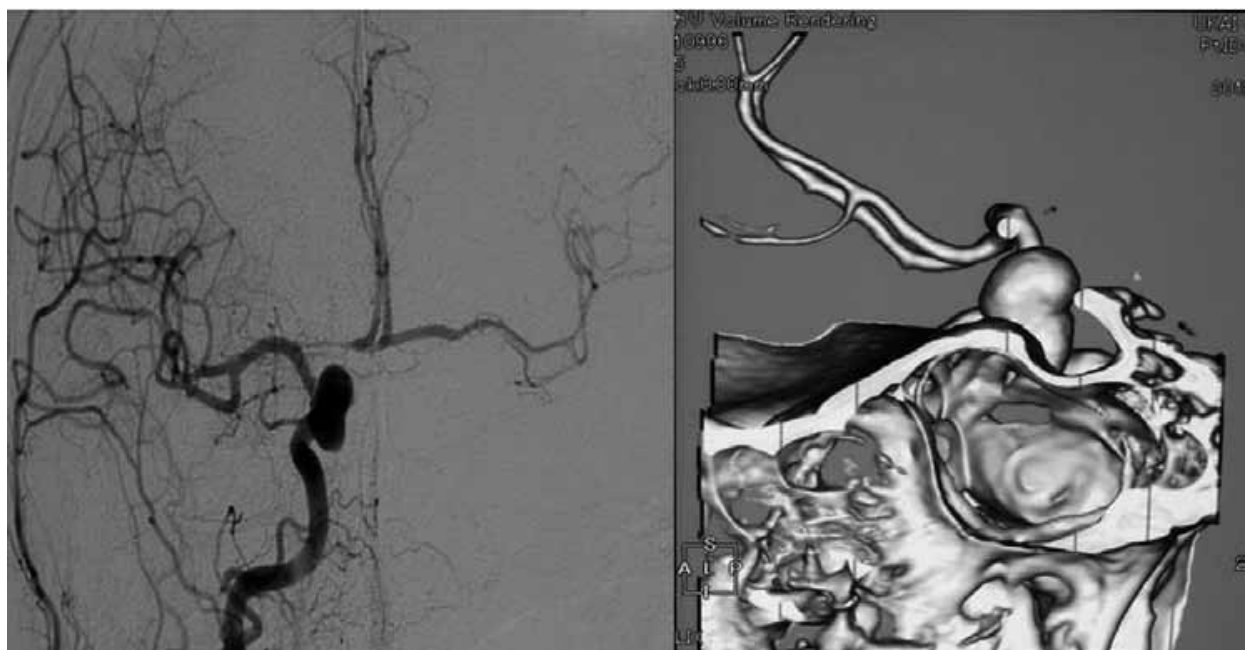

Figure 16: Antero-posterior Digital Subtraction Angiography (DSA) showing paraclinoid ICA aneurysm. Its relation with cavernous sinus and its height below the ACP can be studied well on 3D-CTA.

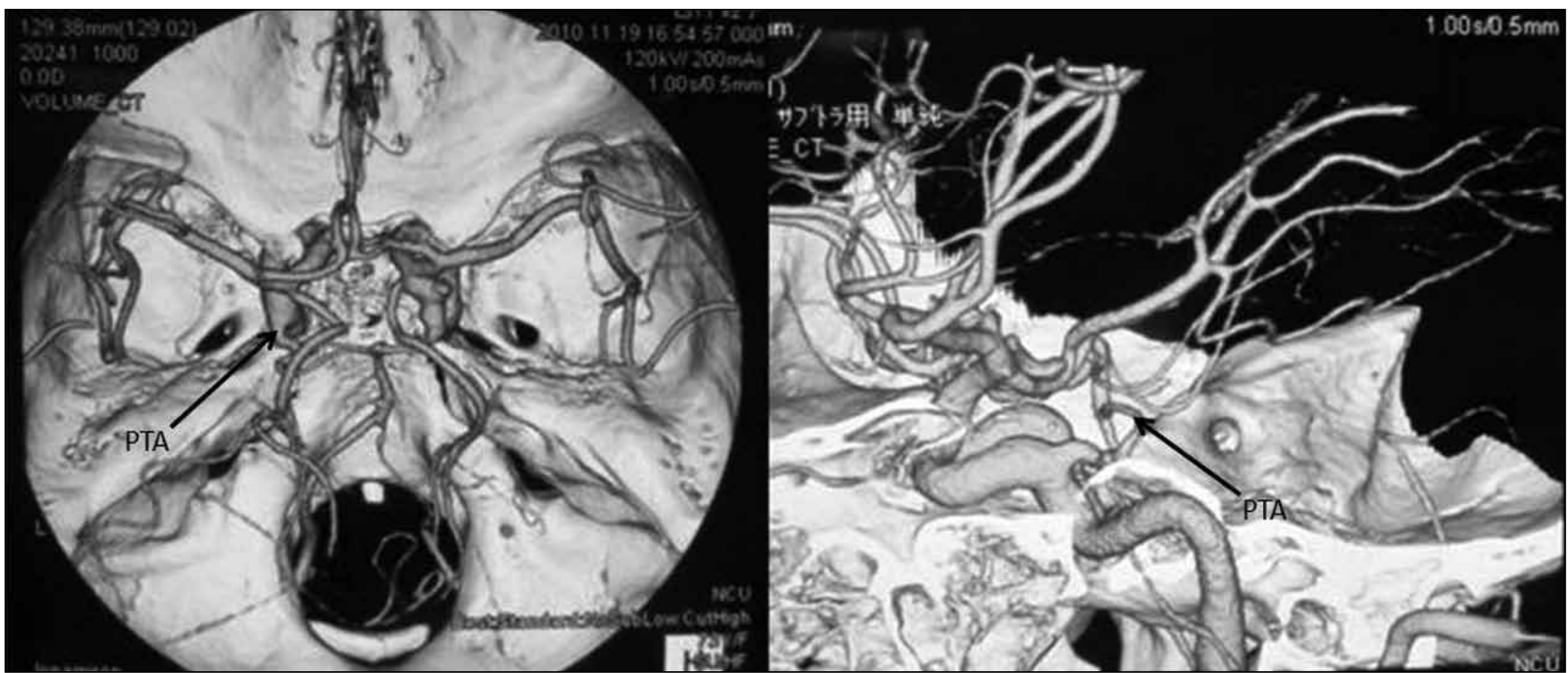

Figure 17: Right Persistent Trigeminal Artery (PTA) seen in a case of Left P-com aneurysm (arrow) forming a communication from Cavernous ICA and Basilar artery (BA). 


\section{REFERENCES}

1. Agid R, Lee SK, Willinsky RA, Farb Rl, terBrugge KG: Acute subarachnoid hemorrhage: Using 64-slice multidetector CT angiography to "triage" patients' treatment. Neuroradiology 48:787-794, 2006

2. Bharatha A, Yeung R, Durant D, Fox AJ, Aviv RI, Howard $P$, et al: Comparison of computed tomography angiography with digital subtraction angiography in the assessment of clipped intracranial aneurysms. J Comput Assist Tomogr 34:440-445, 2010

3. Kallmes DF, Layton K, Marx WF, Tong F: Death by nondiagnosis: Why emergent CT angiography should not be done for patients with subarachnoid hemorrhage. AJNR Am J Neuroradiol 28:1837-1838, 2007

4. Khan N, Ashraf N, Hameed A, Muhammed A: Diagnostic accuracy of $\mathrm{CT}$ angiography and surgical outcome of cerebral aneurysms. Pak Journal of Neurological Sciences 4:8-11, 2009

5. Mani RL, Eisenberg RL, McDonald EJ Jr, Pollock JA, Mani JR: Complications of catheter cerebral arteriography: Analysis of 5,000 procedures. I. Criteria and incidence. AJR Am J Roentgenol 131:861-865,1978
6. Mo DP, Bao SD, Li L, Yi ZQ, Zhang JY, Zhang Y: Virtual reality system for diagnosis and therapeutic planning of cerebral aneurysms. Chin Med J(Engl) 123:2206-2210, 2010

7. Nagai $M$, Watanabe $E$ : Benefits of clipping surgery based on three dimensional computed tomography angiography. Neurol Med Chir (Tokyo) 50:630-637, 2010

8. Sadamasa N, Yoshida K, Narumi O, Chin M, Yamagata S: Trends in mortality rates for subarachnoid hemorrhage, from 1999 through 2008: Single center experience. No Shinkei Geka 38:811-815, 2010

9. Siddiqi J, Harrison M, Al-Mefty O:Threats to the gold standard: Intracranial aneurysm detection with CTA/MRA versus conventional catheter angiography. Crit Rev Neurosurg 7:241-247,1997

10. U-King-Im JM, Koo B, Trivedi RA, Higgins NJ, Tay KY, Cross $J$, et al: Current diagnostic approaches to subarachnoid haemorrhage. Eur Radiol 15:1135-1147, 2005 